\title{
Patterns in Liver-Related Health Outcomes with Hepatitis C Virus Treatments and Health Equity Implications for Decision Makers: A Cohort Analysis of Medicaid Patients
}

S. Mantravadi ${ }^{*}$

\begin{abstract}
Introduction: Hepatitis C virus (HCV) infection is a blood-borne communicable disease that, in perhaps $20 \%$ of cases, results in a chronic disease. However, traditional peginterferon/ribavirin therapies pose many adverse side effects that are difficult to tolerate, and many patients do not complete the therapy. However, healthcare access to these newer, efficacious treatments are reduced, due to inadequate or lack of coverage of direct acting antiviral (DAA) medication. The objective of this study was to evaluate the impact of HCV treatment regimens on outcomes of care for HCV-infected Medicaid beneficiaries without cirrhosis/liver disease scarring.

Methods: A cohort analysis was performed to evaluate the changes in cirrhosis, hepatocellular carcinoma (liver cancer), and liver transplantation with use of HCV treatments in Medicaid beneficiaries with HCV, and was followed over a period of 10 years. The cohort of Medicaid beneficiaries and relevant variables were generated from published literature. Results: Finally, considering the impact on health expenditures due to improved access to new treatments in Medicaid beneficiaries, DAAs resulted in the lowest decompensated cirrhosis and hepatocellular carcinomarelated healthcare cost per person over the 10-year time frame the cohort was followed.

Conclusions: The risk of liver-related disease is higher in patients with cirrhosis, as reaching treatment success results in continued disease progression, not normal health status; thus, liver cancer healthcare costs are higher in patients with cirrhosis, compared to those without cirrhosis.
\end{abstract}

Keywords: hepatitis C; Medicaid; health equity

\section{Introduction}

Hepatitis $\mathrm{C}$ virus (HCV) infection is a blood-borne communicable disease that, in perhaps $20 \%$ of cases, results in a chronic disease, spanning an "indolent course." ${ }^{1}$ The sequela of HCV infection ranges from acute to chronic forms of liver disease, cirrhosis, and liver cancer. ${ }^{2}$ The HCV infection increases the risk of liver-related negative health outcomes. Patients may experience jaundice, dark urine, and nonspecific symptoms such as nausea, fatigue, and anorexia. ${ }^{3,4}$ The HCV infection can result in several degrees of liver fibrosis and damage (cirrhosis).

The level of liver damage is classified based on the grade of inflammation and the stage of fibrosis (F0-F4, where F0 mild hepatitis/no fibrosis), depending on the extent of damage to and inflammation of the liver. ${ }^{5}$ Patients in the compensated cirrhosis (F4) do not experience symptoms of hepatitis, and have a significantly higher survival rate than those with decompensated cirrhosis. ${ }^{6}$

More than 2.7-3.9 million people with $\mathrm{HCV}$ infection live in the United States, and the disease causes long term decreased health related quality of life. ${ }^{4,7,8-15} \mathrm{~A}$ majority of these cases are prevalent rather than incident. ${ }^{16}$ The mortality due to HCV infection now exceeds human immunodeficiency virus in cause specific mortality. ${ }^{4,17}$ Mortality due to HCV infection and liver cancer is predicted to increase, corresponding with the duration of infection. ${ }^{18}$ 
It was forecasted that although the incidence of $\mathrm{HCV}$ infection declined during the 1990s, individuals infected for more than 20 years would increase substantially before cresting in $2015 .^{19}$ Due to lack of HCV screening of blood supplies before 1992, individuals who have had blood transfusions/exposure may be at a higher risk for HCV. ${ }^{20}$ The peak of HCV infection prevalence occurs in the population younger than 55 years and disproportionally affects the poor. ${ }^{21,22}$

Treatment to reach sustained virologic response is desirable as this reduces the risk for the noted sequelae of HCV infection. ${ }^{10}$ Sustained virologic response is attained when the hepatitis $\mathrm{C}$ viral RNA cannot be detected in the patient's bloodstream for 6 months. ${ }^{23,24}$ Length of treatment for peginterferon and ribavirin regimens can be 48 weeks, with weekly peginterferon injections and ribavirin pills taken once daily, orally. ${ }^{25}$ However, traditional peginterferon/ribavirin therapies pose many adverse side effects that are difficult to tolerate, and many patients do not complete the therapy. ${ }^{26}$ A new wave of treatments for HCV infection entered the market, with the approval of direct acting antivirals (DAAs) by the Food and Drug Administration. Currently approved DAA treatments include simeprevir, sofosbuvir, ledipasvir, ombitasvir/paritaprevir/ ritonavir with dasabuvir, daclatasvir-sofosbuvir, elbasvirgrazoprevir, and most recently, sofosbuvir-velpatasvir., ${ }^{4,29}$

Before the newly approved oral DAA agents, most newly detected cases of $\mathrm{HCV}$ infection did not prompt antiviral medication due to side effects and limited efficacy of peginterferon/ribavirin regimens. Health disparities arise since the disease progresses slowly and chronic $\mathrm{HCV}$-infected patients often play a waiting game for treatment, either due to efficacy or affordability of effective treatments, putting health outcomes at risk.

Risk of HCV infection and subsequent health disparities are higher for certain populations, including low income. ${ }^{30,31}$ The presence of HCV infection was found to be associated with Medicaid and public insurance usage. ${ }^{32}$ There will be a reduction in the number of low-income individuals who are uninsured, as with the Affordable Care Act there is increased eligibility for Medicaid services and coverage. ${ }^{31,33,34}$ This results in a large number of $\mathrm{HCV}$-infected individuals who qualify for Medicaid. ${ }^{34}$ In addition, HCV infection screening/testing for high-risk patients is usually considered part of routine preventive services in non-grandfathered traditional Medicaid plans ${ }^{15}$; the Department of Health and Human Services is encouraging $\mathrm{HCV}$ testing ${ }^{35}$ and screening initiatives.
The number of Medicaid beneficiaries with HCV infection is high, and the number is rising, as the proportion of new Medicaid beneficiaries identified as infected with HCV will continue to increase. ${ }^{31,33}$ There are 377,000 Medicaid beneficiaries who are HCV positive (all HCV genotypes), reported in $2013 .{ }^{31}$ In 2015 , the payer forecasts that the number of $\mathrm{HCV}$-infected Medicaid beneficiaries will be from 401,390 to $444,010 .^{31}$ Hence, the Medicaid population is at greater risk; treatment of HCV infection is a priority for Medicaid.

However, healthcare access to these newer, efficacious treatments is reduced, due to inadequate or lack of coverage of DAA medication. Sofosbuvir has been considered a nonpreferred drug on the tiered formularies in a majority of Medicaid programs; many states also consider liver disease severity/presence of cirrhosis as a criteria for coverage of DAA medications. ${ }^{30,36}$ Restricting treatment coverage has negative consequences on health of patients, public health of the population, opportunities for reduction of transmission among Medicaid beneficiaries, and treatment affordability/availability. ${ }^{37,38}$

Many dimensions of HCV health disparities influence access to DAA treatment, including socioeconomics, availability of/access to care, and health insurance coverage. Individuals with inadequate health insurance coverage, as often occurs with Medicaid, have a lower chance of receiving appropriate medical care, and are more likely to have poor health status. ${ }^{39}$ Furthermore, several barriers arise when considering access to services-including high costs/low affordability of services/treatment, lack of insurance coverage of services (Healthy people, 2020).

Such barriers lead to preventable hospitalizations and negative health outcomes, delays in care, and unmet preventive services. ${ }^{39}$ In the case of HCV patients on Medicaid, lack of coverage for DAA medications leads to cases of potentially preventable negative liver-related health outcomes, treatments for liver cancer, and liver transplantations.

Health outcomes for HCV-infected Medicaid patients are already at a disadvantage. What would happen if you introduce DAA as a treatment, compared to current options for treatment? This is further explored in this study.

\section{Materials and Methods}

The objective of this study was to evaluate the impact of $\mathrm{HCV}$ treatment regimens on outcomes of care for HCV-infected Medicaid beneficiaries without cirrhosis/ liver disease scarring. Specifically, this study aimed to compare what happens to a cohort of patients without 
cirrhosis on Medicaid, and follow such a cohort over 10 years.

A cohort analysis was performed to evaluate the changes in cirrhosis, hepatocellular carcinoma, and liver transplantation with use of $\mathrm{HCV}$ treatments in Medicaid beneficiaries with $\mathrm{HCV}$, and was followed over a period of 10 years. The cohort of Medicaid beneficiaries used a sample generated from published literature. The target population was the noninstitutionalized Medicaid population in the United States with a diagnosis of HCV infection. The data source is from published literature ${ }^{31}$ and publically available reports. ${ }^{15}$ The model considered 72,164 patients with HCV with cirrhosis on Medicaid, using data from public literature estimates, ${ }^{40}$ and age/genotype distributions of HCV. The study cohort was limited to Medicaid beneficiaries, 55 years and younger.

The National Average Drug Acquisition Cost values, as published by Mediciad, ${ }^{41}$ as well as wholesale cost were used for medication costs of American Association for the Study of Liver Diseases and the Infectious Diseases Society of America ${ }^{42}$ recommended treatments for HCV genotype 1a patients without cirrhosis. The treatments considered in this cohort analysis were ribavirin, peginterferon, sofosbuvir, simeprevir-sofosbuvir, sofosbuvir-velpatasvir, ombitasvir/paritaprevir/ritonavir, and dasabuvir. Furthermore, the effectiveness of each DAA treatment was extracted from published articles on clinical trials. Table 1 illustrates the data used in the cohort analysis.

These American Association for the Study of Liver Diseases and the Infectious Diseases Society of America recommended medications were evaluated in the context of a watch/wait scenario (no treatment for oncogenic disease) and peginterferon-ribavirin. Since DAAs are not fully covered for Medicaid patients due to high medication costs, peginterferon-ribavirin is considered as an alternative treatment option. Furthermore, since many providers are reluctant to treat patients with peginterferon-ribavirin due to side effects and low efficacy, a watch and wait strategy is often considered.

The cohort progressed through the natural history of HCV disease stages. The treatment is successful if the individual reaches sustained virologic response. All patients in the cohort analysis began at a baseline of HCV infection, without liver cirrhosis/scarring (F0F3). The individual is treated, by one of the noted regimens, and either (1) reaches sustained virologic response or (2) fails to reach sustained virologic response. Patients who failed to reach sustained virologic response were modeled to be retreated in year 2; each individual in the Medicaid cohort had a $50 \%$ chance of retreatment, illustrating the implicit effects of access to care and affordability of DAA medications. If the patient reaches sustained virologic response from F0 to F3, the patient reaches a normal health status. If the patient does not reach sustained virologic response, the patient continues into disease progression stages of liver damage.

Each disease stage had a bivariate decision; the individual with liver damage may stay in the same health stage or progress. At each of the 10 years, each patient can progress from the following:

- F0-F3 to F4/compensated cirrhosis liver damage state.

- From F4 liver damage state to decompensated cirrhosis or liver cancer.

- From decompensated cirrhosis state to liver cancer or liver transplantation. ${ }^{43,44}$

Patients who are in liver cancer state can either continue with liver cancer or move to liver transplantation state.

Thus, liver transplantation, liver cancer, and decompensated cirrhosis are endpoints in the model. Each event in the natural history/disease progression occurs on a yearly basis. All treatment-naive patients were started at the same baseline and will continue through the natural history progression.

This study was based entirely on the use of published literature and costs. These are publicly available, published sources, which omit patient-level, personal identification information. The Medicaid National Average Drug Acquisition Cost data set is an aggregated, publically available data set on costs of medications. In addition, published literatures on HCV infection were used. Since there was no risk posed to human subjects in this research, this study met the exempt status by the University of Texas Health Science Center Committee for Protection of Human Subjects.

Over the 10-year period of time, the all-cause healthcare costs in the Medicaid HCV cohort for liver-related outcomes (decompensated cirrhosis, compensated cirrhosis, hepatocellular carcinoma, and liver transplantation) that were averted by each treatment were evaluated. The Medicaid cohort's disease progression through the HCV natural stages was also determined.

\section{Results}

The cohort analysis of Medicaid beneficiaries without cirrhosis indicated that patients on DAA treatments 
Table 1. Cohort Analysis: Values for Simulated Cohort

\begin{tabular}{|c|c|c|}
\hline Input value/variable & References & Base case value (range)/probabilities \\
\hline \multicolumn{3}{|l|}{ Rate variable: treatment response rate (SVR reached) } \\
\hline No treatment & 43 & $1 \%(0.7-1.7 \%)$ \\
\hline Peginterferon-ribavirin & Pegasys, Pegintron, Copegus, Rebetol & $41 \%(38-44 \%)$ \\
\hline Elbasvir-grazoprevir, 12 weeks & C-EDGE TN & $92 \%(94 \%)$ \\
\hline Harvoni (sofosbuvir-ledipasvir), 12 weeks & $\begin{array}{l}\text { ION 1,3; NEUTRINO trial; ION 1, double blind; } \\
\text { NEUTRINO, open label }\end{array}$ & $\begin{array}{l}96 \% \text { (89-100); Gilead'16; range-genotype } \\
1 \text { Rx naive NC; ION 1, 96-100; } \\
\text { ION 3, 95-98; NEUTRINO, 89-95 }\end{array}$ \\
\hline $\begin{array}{l}\text { Simeprevir-sofosbuvir without } \\
\text { ribavirin, } 12 \text { weeks }\end{array}$ & $\begin{array}{l}\text { ION 1,3; NEUTRINO trial; ION 1, double blind; } \\
\text { NEUTRINO, open label }\end{array}$ & $\begin{array}{l}97 \%(97 \%) ; \text { Base case-treatment naive, } \\
\text { noncirrhosis genotype } 1 \\
\text { range-genotype } 1 \mathrm{a}\end{array}$ \\
\hline Viekira Pak-ribavirin 12 weeks & Pearl IV; Saphire I & $95.3 \%(93-97.6 \%)$ \\
\hline Daclatasvir-sofosbuvir & ALLY-1 & $96.4 \%$ \\
\hline \multicolumn{3}{|l|}{ Transition probabilities for cohort } \\
\hline F3 to F4 & 43 & 0.116 \\
\hline F4 with SVR to decompensated cirrhosis & 43 & 0.008 \\
\hline F4 without SVR to decompensated cirrhosis & 43 & 0.039 \\
\hline F4 with SVR to liver cancer & 43 & 0.005 \\
\hline F4 without SVR to liver cancer & 43 & 0.014 \\
\hline Decompensated cirrhosis to liver cancer & 43 & 0.068 \\
\hline Decompensated cirrhosis to liver transplant & 43 & 0.023 \\
\hline \multicolumn{2}{|l|}{ Treatment cost/day } & $\$$ \\
\hline Pegylated interferon- ribavirin & Medicaid National Average Drug Acquisition Cost & $\begin{array}{l}\text { Pegylated interferon (pegasys proclick): } \\
1685.5(1264.15-2106.8) ; \text { ribavirin: } \\
0.87(0.66-1.1)\end{array}$ \\
\hline Elbasvir-grazoprevir & Medicaid National Average Drug Acquisition Cost & Elbasvir-grazoprevir: 650 (487.5-812.5) \\
\hline Sofosbuvir-velpatasvir & & Sofosbuvir-velpatasvir: $890(667.5-1112.5)$ \\
\hline Sofosbuvir-ledipasvir & Medicaid National Average Drug Acquisition Cost & Sofosbuvir-ledipasvir: 1091.2 (818.4-1364.0) \\
\hline Simeprevir-sofosbuvir & Medicaid National Average Drug Acquisition Cost & $\begin{array}{l}\text { Sofosbuvir: } 981.5 \text { (736.13-1226.9) } \\
\text { Simeprevir: } 781.2(585.96-76.5)\end{array}$ \\
\hline Ombitasvir-daclatasvir-paritaprevir-ribavirin & Medicaid National Average Drug Acquisition Cost & $\begin{array}{l}\text { Viekira Pak: } 243.5 \text { (182.65-304.4) } \\
\text { Ribavirin: } 0.9(0.7-1.1)\end{array}$ \\
\hline Daclatasvir-sofosbuvir & Medicaid National Average Drug Acquisition Cost & $\begin{array}{l}\text { Sofosbuvir: } 981.50 \text { (736.1-1226.9) } \\
\text { Daclatasvir: } 723.625 \text { (542.74-904.53) }\end{array}$ \\
\hline \multicolumn{2}{|l|}{ Cost: total/all-cause healthcare cost/year } & $\$ /$ year \\
\hline HCV infection monitoring & 31,43 & $14,915.00(14464-16686)$ \\
\hline Decompensated cirrhosis & 31,43 & $41,943.00$ (38670-44936) \\
\hline Compensated cirrhosis & 31,43 & $16,911.00(15313-26354)$ \\
\hline Liver cancer & 31,43 & $58,208.00(50878-66116)$ \\
\hline $\begin{array}{l}\text { Liver transplant + medical cost, } \\
\text { first and subsequent years }\end{array}$ & 31,43 & $\begin{array}{l}190,995.00(182,973-199,017) \\
S D=8022 ; \text { subsequent years: } 54,885.00 \\
\quad(50,476-59,294) ; S D=4409.00\end{array}$ \\
\hline
\end{tabular}

F0-F3, where F0 is mild hepatitis; HCV, hepatitis C virus; SD, standard deviation; SVR, sustained virological response.

had lower incidence of liver-related outcomes, as well as all-cause healthcare costs. Since reaching treatment success results in reaching a healthy state, only individuals who do not reach sustained virologic response are at a higher risk for liver-related conditions. Thus, when following the cohort after the 10-year period, the number of individuals and the associated costs of liver-related outcomes are low in patients on DAA treatments. Since treatment success prevents disease progression of $\mathrm{HCV}$ natural history, patients without cirrhosis have reduced overall disease progression; among those in the cohort who progressed to endstage liver disease outcomes, most of the cohort was in early stages. This results in overall improved out- comes, lowered medical costs accrued, and higher savings/averted medical costs.

Furthermore, the cohort analysis, presented in Table 2, of Medicaid beneficiaries illustrated that DAA treatments resulted in the lowest number of individuals in end-stage liver disease-related outcomes, over the 10-year progression of the cohort, as in Table 2. Approximately 600 individuals were in decompensated cirrhosis, after the 10-year time period, while with peginterferon-ribavirin treatment, there were 3334 individuals with decompensated cirrhosis.

The cohort analysis revealed that progression of the patient through disease stages is affected by the treatment choice. DAA treatments resulted in a higher number of 


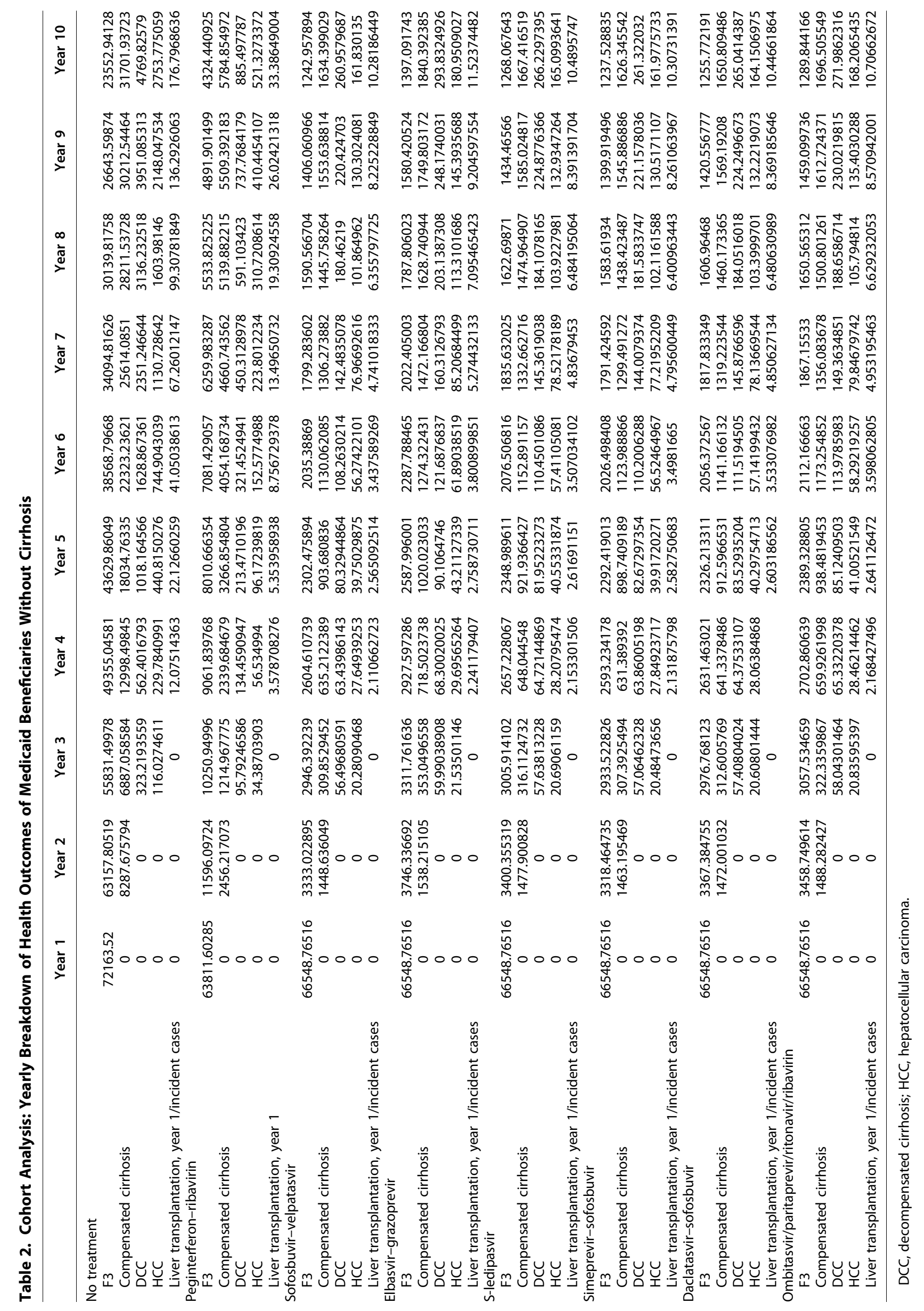


Table 3. Cohort Analysis-Year 10: Health Outcomes of Medicaid Beneficiaries Without Cirrhosis

\begin{tabular}{lcccc}
\hline Treatment regimen & $\begin{array}{c}\text { Number of individuals } \\
\text { who reached SVR after } \\
\text { treatment regimen completion }\end{array}$ & $\begin{array}{c}\text { Total number of } \\
\text { individuals in } \\
\text { DCC at year 10 }\end{array}$ & $\begin{array}{c}\text { Total number of } \\
\text { individuals in } \\
\text { HCC at year 10 }\end{array}$ & $\begin{array}{c}\text { Total number of } \\
\text { individuals progressing } \\
\text { to liver transplantation } \\
\text { at year 10 }\end{array}$ \\
\hline No treatment & 718.0390212 & 17417.82387 & 9052.036126 & 554.9095422 \\
Peginterferon-ribavirin & 21463.03262 & 3334.065134 & 1771.579724 & 109.9058527 \\
Sofosbuvir-velpatasvir & 41572.28156 & 1056.360701 & 594.6383436 & 37.71725391 \\
Elbasvir-grazoprevir & 40027.81508 & 1185.552264 & 659.6587963 & 41.8990499 \\
Sofosbuvir-ledipasvir & 41067.71641 & 1077.700886 & 606.6509947 & 38.47920311 \\
Simeprevir-sofosbuvir & 41321.25708 & 1064.804802 & 596.1214544 & 37.97773475 \\
Daclatasvir-sofosbuvir & 41169.43703 & 1078.643501 & 603.4126605 & 38.42803146 \\
Ombitasvir/paritaprevir/ritonavir/ribavirin & 40888.72333 & 1104.465267 & 617.0107364 & 39.26761301 \\
\hline
\end{tabular}

individuals who reached sustained virologic response; as in Table 3, within those who did not reach treatment success, DAA treatment illustrated there was a higher percentage of the Medicaid cohort that remained in earlier stage of disease. For DAA-based regimens, the number of individuals in decompensated cirrhosis progressed from $\sim 60$ to 260 , over the 10-year cohort analysis. In addition, as demonstrated in Table 3, DAA regimens showed that endstage liver disease outcomes, such as liver transplantation, were low; after 10 years, the number of individuals with liver transplantation in the cohort increased by $\sim 20$. Peginterferon-ribavirin regimens showed that cohort progression toward liver transplantation increased by 97 patients, after the 10-year period of time.

Finally, considering the impact on health expenditures due to improved access to DAAs in Medicaid beneficiaries, as shown in Table 4, Sofosbuvir-velpatasvir also resulted in the lowest decompensated cirrhosis and hepatocellular carcinoma-related healthcare cost per person, over the 10-year time frame the cohort was followed. The next treatment option that resulted in lowered negative liverrelated outcomes as well as reduced health expenditures is elbasvir-grazoprevir and sofosbuvir-ledipasvir.

Within the Medicaid cohort of HCV patients, sensitivity analysis concerning the retreatment of hepatocellular cancer during the second year of follow-up was conducted, to illustrate the effects of retreatment. The retreatment of all or none of the patients who did not reach treatment success was analyzed. The retreatment of all eligible patients (those who did not reach treatment success), illustrated higher savings/averted medical costs and improved outcomes. Thus, compared to not retreating the cohort, it is evident that there is a pattern of reduced number of negative health outcomes for patients, which arises in retreatment of all eligible cohort patients.

\section{Discussion}

This study demonstrates the importance of treatment with DAAs for patients in the early stages of the disease (without cirrhosis) to prevent cirrhosis and the negative outcomes associated with HCV infection. Furthermore, the result of this cohort analysis has many health equity implications for Medicaid beneficiaries with $\mathrm{HCV}$, especially in terms of improved access to DAA medications within Medicaid.

Currently, many Medicaid beneficiaries do not have access to DAAs, as coverage is restricted toward patients with cirrhosis/liver disease. It becomes evident that the primary impact of DAAs on patients with and without cirrhosis is driven by the number of individuals in earlier stages of the disease. ${ }^{45}$ The risk of liver-related disease is higher in patients with cirrhosis, as reaching treatment success results

Table 4. Cohort Analysis-Year 10: Healthcare Costs of Medicaid Beneficiaries Without Cirrhosis

\begin{tabular}{|c|c|c|c|c|c|c|}
\hline Treatment regimen & $\begin{array}{c}\text { HCC } \\
\text { healthcare } \\
\text { costs per } \\
10 \text { years }\end{array}$ & $\begin{array}{c}\text { HCC } \\
\text { healthcare } \\
\text { costs per } \\
\text { person }\end{array}$ & $\begin{array}{c}\text { DCC } \\
\text { healthcare } \\
\text { costs per } \\
10 \text { years }\end{array}$ & $\begin{array}{c}\text { DCC } \\
\text { healthcare } \\
\text { costs per } \\
\text { person }\end{array}$ & $\begin{array}{l}\text { Liver transplantation } \\
\text { (first year/total } \\
\text { incident cases) } \\
\text { healthcare costs } \\
\text { per } 10 \text { years }\end{array}$ & $\begin{array}{l}\text { Liver transplantation } \\
\text { (first year/total } \\
\text { incident cases) } \\
\text { healthcare costs } \\
\text { per person }\end{array}$ \\
\hline No treatment & $\$ 435,443,320.89$ & $\$ 6,034.12$ & $\$ 645,476,757.68$ & $\$ 8,944.64$ & $\$ 92,292,676.44$ & $\$ 1,278.94$ \\
\hline Peginterferon-ribavirin & $\$ 84,830,588.40$ & $\$ 1,175.53$ & $\$ 124,014,066.74$ & $\$ 1,718.51$ & $\$ 18,347,552.27$ & $\$ 254.25$ \\
\hline Sofosbuvir-velpatasvir & $\$ 28,178,598.18$ & $\$ 390.48$ & $\$ 39,633,801.65$ & $\$ 549.22$ & $\$ 6,346,233.61$ & $\$ 87.94$ \\
\hline Elbasvir-grazoprevir & $\$ 31,295,432.78$ & $\$ 433.67$ & $\$ 44,448,636.24$ & $\$ 615.94$ & $\$ 7,044,797.83$ & $\$ 97.62$ \\
\hline Sofosbuvir-ledipasvir & $\$ 28,747,851.20$ & $\$ 398.37$ & $\$ 40,434,468.20$ & $\$ 560.32$ & $\$ 6,474,437.74$ & $\$ 89.72$ \\
\hline Simeprevir-sofosbuvir & $\$ 28,246,885.35$ & $\$ 391.43$ & $\$ 39,964,659.74$ & $\$ 553.81$ & $\$ 6,391,230.83$ & $\$ 88.57$ \\
\hline Daclatasvir-sofosbuvir & $\$ 28,596,628.34$ & $\$ 396.28$ & $\$ 40,478,671.63$ & $\$ 560.93$ & $\$ 6,466,297.87$ & $\$ 89.61$ \\
\hline Ombitasvir/paritaprevir/ritonavir/ribavirin & $\$ 29,248,963.84$ & $\$ 405.32$ & $\$ 41,437,692.90$ & $\$ 574.22$ & $\$ 6,606,249.52$ & $\$ 91.55$ \\
\hline
\end{tabular}


in continued disease progression, not normal health status; thus, the liver cancer healthcare costs are higher in patients with cirrhosis, compared to those without cirrhosis. However, this indicates that DAAs are more cost saving in the case of patients without cirrhosis (early stage). Since DAAs are highly effective, and reaching sustained virologic response results in avoidance of disease progression of HCV natural history, the costs associated with a cohort of patients treated with DAAs are low, emphasizing the importance of early treatment.

Essentially, treatment and HCV disparities influence health services. Thus, the results of this study can be placed in the context of conceptual frameworks/theory of the Andersen-Aday model.

The Andersen-Aday model explains health services utilization as a function of population and delivery system characteristics. The Andersen-Aday model illustrates disparities and health equity issues in $\mathrm{HCV}$ treatment utilization, where age, gender, race/ethnicity, income, education, occupation, consumer behavior, place of birth/citizenship status, comorbidities predispose certain groups as vulnerable to HCV. Insurance status/coverage, regular source of care, screenings/tests are the major components of the delivery system that enable utilization of services and treatment. Along with predisposing and enabling factors, perceived/medical need affects the realized access-that is, actual use of care, which in turn improves health outcomes.

Health equity then needs to be considered in terms of access to DAAs/health services-for prescription. The implications of this analysis aids in the clarification of prescription drug coverage for Medicaid beneficiaries and current restrictions. ${ }^{38}$ Coverage for sofosbuvirledipasvir in Medicaid patients is restricted by physician type, for $2 / 3$ rds of states. ${ }^{30}$ Another manner for denying DAA is to restrict its prescription to specialists, and not by general practitioners or primary care physicians. ${ }^{30}$ The 30 states that cover sofosbuvir for treatment of HCV infection have prior authorization criteria that require sofosbuvir to be prescribed by a gastroenterologist, hepatologist, or liver infectious disease specialist. ${ }^{30,36}$ Lack of an usual source of care can infringe on access to care and treatments. ${ }^{46}$ Difficulties with entry to the healthcare system, as well as accessing specialist care in an available location, often occur to patients with inadequate coverage, or those on Medicaid. In certain states, coverage for DAAs is also restricted by limits on weekly refills, the investigation of prior pharmacy refill records to estimate patient adherence; these restrictions may not be feasible for patients due to transportation limitations. ${ }^{36}$
Furthermore, the achievement of health equity for $\mathrm{HCV}$ patients is dependent on not limiting access to treatment based on disease severity.

The Centers for Medicare and Medicaid Services have issued a letter to states on the health disparity issues that arise with prescription coverage; the agency is concerned that managed care plans are more stringent than fee for service Medicaid regarding the coverage of DAAs. ${ }^{47}$ The uptake of these medications is low due to the issue of affordability and coverage, especially for Medicaid patients. ${ }^{37}$ The Medicare/Medicaid dual eligible populations, who have compounded risk factors for HCV infection due to age and low-income status, are especially at risk for reduced access to medications due to affordability.

Since the use of DAAs provides strong cost savings, states may also want to review policies and consider changing those that otherwise interfere with access, such as lack of network specialists and associated stigma from approval criteria. As shown in a study of HCV screening and treatment in southeast Michigan, Medicaid patients who screened positive for $\mathrm{HCV}$ were more likely to have inadequate care coordination and linkage between providers. ${ }^{48}$

The goal of eliminating HCV is precluded by screening, delivery coordination, and disparities in clusters of vulnerable populations. The combination of a scale up strategy with a physician-based promotion of DAA treatment as prevention would address gaps in care. ${ }^{49,50}$ The advent of new pangenotypic treatments, such as sofosbuvir-velpatasvir, and coordination among Medicaid stakeholders and multiple payers create a direction toward improved care delivery and a quick scale-up strategy for treatment. ${ }^{50}$

Patients are often facing drug authorization issues through Medicaid ${ }^{30,46,51,52}$; due to issues with authorization and coverage, the public health of the community is at risk, with the avoidance of the medication costs associated with a cure for the viral infection, ${ }^{38}$ the public health benefit of addressing health disparity in hepatitis $\mathrm{C}$ needs to be balanced. ${ }^{50}$ Furthermore, unintended consequences in the entire healthcare system may be a result of changes in pharmacy benefits for Medicaid patients. ${ }^{46,50}$ In addition, with changes in approval of coverage, costs of physician paperwork burden for prior authorization, documentations of treatment history, and appeals of medical necessity will change, further affecting delay in treatments and potential public health benefit from reduced transmission and individual health outcome risks.

The results of this study indicate that despite real-world variation in treatment discontinuation, implementation 
of coverage for DAAs results in savings for Medicaid. One of the biggest critiques of Medicaid coverage for DAAs is that patients must be adherent to treatment regimens although there is no strong evidence that discontinuation affects outcomes, in HCV interferon-based treatments ${ }^{46,52-56}$; currently, an area for future research is to evaluate whether this is consistent in oral DAA medications. ${ }^{46,52-56}$ The sensitivity analysis conducted in this study shows that even when there is $8.3 \%$ treatment discontinuation, there is still overall benefit to Medicaid, as the benefit of treatment is averaged out.

The Office of Health Equity has recognized the importance of the disparities that exist within $\mathrm{HCV}$ and the contribution of this disease toward advanced liver disease outcomes, with the development of the Hepatitis C-Advanced Liver Disease Disparities Dashboard, using data from the VA system. ${ }^{57}$ The dashboard allows for views of vulnerable areas for targeting interventions to improve health disparities within the VA population. ${ }^{57}$ Building on this work with additional vulnerable populations, especially Medicaid and dual eligible Medicare/Medicaid beneficiaries, would aid in increasing the coordination among siloed physician groups and payers, as well as the availability of evidence for decision makers. Increasing access to information regarding the impact of disparities in care and treatment would improve targeting of care.

\section{Conclusion}

The Medicaid population is at a high risk for HCV infection, due to socioeconomic burdens and lack of financial resources. ${ }^{30,31}$ In this study, we have discussed how increased coverage of DAA treatments can improve efforts toward reduced risk of long-term negative health outcomes, especially liver cancer, for patients with $\mathrm{HCV}$. Efforts toward increased DAA coverage and affordability are urgent, as early treatment of individuals with early stages of HCV can aid the burden of disparities. The high prevalence in HCV, especially in vulnerable and disproportionately affected populations such as Medicaidinsured African Americans, Asian Americans and Pacific Islanders, Hispanics and Latinos, and Native Americans, means that this disease is a challenge from both health outcome and cost long-term perspectives (health affairs).

With the looming impact of DAA treatment on Medicaid and health disparities, this study provides a foundation for the coordinated actions of decision makers, providers, and Medicaid analysts to value treatments in the context of long-term prevention, and management of HCV toward the goal of health outcomes and equity. ${ }^{58}$

\section{Author Disclosure Statement}

No competing financial interests exist.

\section{References}

1. McHutchison JG, Bacon BR, Owens GS. Making it happen: managed care considerations in vanquishing hepatitis C. Am J Manag Care. 2007;13:S327.

2. World Health Organization. [Homepage]. 2016. Available at www.who.int/ en/ Accessed May 20, 2016.

3. Klevens RM, Hu DJ, Jiles R, et al. Evolving epidemiology of hepatitis $C$ virus in the United States. Clin Infect Dis. 2012;55(suppl 1):S3-S9.

4. Belousova V, Abd-Rabou AA, Mousa SA. Recent advances and future directions in the management of hepatitis $C$ infections. Pharmacol Ther. 2015;145:92-102.

5. Cox-North PP, Shuhart MC. Hepatitis C online: core concepts. Evaluation and staging of liver fibrosis. 2015. Available at www.hepatitisc.uw.edu/ go/evaluation-staging-monitoring/evaluation-staging/core-concept/all Accessed June 15, 2016.

6. Thornton. Core concepts. evaluation and prognosis of patients with cirrhosis. University of Washington. 2015. Available at www.hepatitisc.uw.edu/go/evaluation-staging-monitoring/evaluationprognosis-cirrhosis/core-concept/all Accessed May 12, 2016.

7. Food and Drug Administration. [Homepage]. 2016. Available at www.fda.gov/ Accessed July 10, 2016.

8. Bezemer G, Van Gool AR, Verheij-Hart E, et al. Long-term effects of treatment and response in patients with chronic hepatitis $C$ on quality of life. An international, multicenter, randomized, controlled study. BMC Gastroenterol. 2012;12:11.

9. Zetterman RK. HCV treatment: where we're at, where we're going. 2013. Available at www.medscape.com/viewarticle/817546 Accessed July 19, 2016.

10. Veterans Affairs. (2016). Homepage. Available at www.va.gov/ Accessed January 5, 2017.

11. Afdhal N, Zeuzem S, Kwo $P$, et al. Ledipasvir and sofosbuvir for untreated HCV genotype 1 infection. N Engl J Med. 2014;370:1889-1898.

12. Afdhal N, Reddy, KR, Nelson, DR, et al. Ledipasvir and sofosbuvir for previously treated HCV genotype 1 infection. N Engl J Med. 2014;370:1483-1493.

13. Kowdley KV, Gordon SC, Reddy KR, et al. Ledipasvir and sofosbuvir for 8 or 12 weeks for chronic HCV without cirrhosis. N Engl J Med. 2014;370:1879-1888.

14. Armstrong GL, Wasley A, Simard EP, et al. The prevalence of hepatitis $C$ virus infection in the United States, 1999 through 2002. Ann Intern Med. 2006;144:705-714.

15. Centers for Disease Control and Prevention. [Homepage]. 2016. Available at www.cdc.gov/ Accessed December 15, 2016.

16. Ditah I, Ditah, F, Devaki $P$, et al. The changing epidemiology of hepatitis $C$ virus infection in the United States: national health and nutrition examination survey 2001 through 2010. J Hepatol. 2014;60:691-698.

17. Ly KN, Xing J, Klevens RM, et al. The increasing burden of mortality from viral hepatitis in the United States between 1999 and 2007. Ann Intern Med. 2012;156:271-278.

18. Davis $\mathrm{GL}$, Alter MJ, El-Serag H, et al. Aging of hepatitis $\mathrm{C}$ virus (HCV)-infected persons in the United States: a multiple cohort model of HCV prevalence and disease progression. Gastroenterology. 2010;138:513-521.

19. Armstrong GL, Alter MJ, McQuillan GM, et al. The past incidence of hepatitis $C$ virus infection: implications for the future burden of chronic liver disease in the United States. Hepatology. 2000;31:777-782.

20. U.S. Preventive Services Task Force. Final recommendation statement hepatitis C: screening. 2013. Available at www.uspreventiveservicestask force.org/Page/Document/RecommendationStatementFinal/hepatitis-cscreening Accessed July 18, 2016.

21. Menzin J, White LA, Nichols C, et al. The economic burden of advanced liver disease among patients with hepatitis $C$ virus: a large state Medicaid perspective. BMC Health Serv Res. 2012;12:459.

22. Rice JP. Hepatitis $C$ treatment: back to the warehouse. Clin Liver Dis. 2015;6:27-29.

23. Shiratori $Y$, Ito $Y$, Yokosuka $O$, et al. Antiviral therapy for cirrhotic hepatitis $\mathrm{C}$ : association with reduced hepatocellular carcinoma development and improved survival. Ann Intern Med. 2005;142:105-114.

24. Singal AG, Volk ML, Jensen $D$, et al. A sustained viral response is associated with reduced liver-related morbidity and mortality in patients with hepatitis C virus. Clin Gasteroenterol Hepatol. 2010;8:280-288. 
25. Pharmaceutical Research and Manufacturers of America. Twenty-five years of progress against hepatitis C: setbacks and stepping stones. 2014 Available at www.phrma.org/sites/default/files/pdf/Hep-C-Report-2014Stepping-Stones.pdf Accessed June 11, 2015.

26. Alter HJ, Liang TJ. Hepatitis C: the end of the beginning and possibly the beginning of the end. Ann Intern Med. 2012;156:317-318.

27. Kiser JJ, Flexner C. Direct-acting antiviral agents for hepatitis $C$ virus infection. Annu Rev Pharmacol Toxicol. 2013;53:427-449.

28. Merck Sharp \& Dohme Corp (Merck). Merck voluntarily discontinuing VICTRELIS ${ }^{\circledR}$ (boceprevir) $200 \mathrm{mg}$ Capsules. 2015. Available at www.fda.gov/downloads/drugs/drugsafety/drugshortages/ ucm430818.pdf Accessed December 18, 2016.

29. University of Washington. Hepatitis $C$ online. Available at www.hepatitisc.uw.edu/ Accessed December 15, 2016

30. Barua,, Greenwald R, Grebely J, et al. Restrictions for Medicaid reimbursement of sofosbuvir for the treatment of hepatitis $C$ virus infection in the United States. Ann Intern Med. 2015;163:215-223.

31. Milliman, Inc. Health care reform and hepatitis c: a convergence of risk and opportunity. 2013. Available at http://us.milliman.com/uploadedFiles/ insight/2013/convergence-of-risk-and-opportunity.pdf Accessed May $19,2016$.

32. Stepanova M, Kanwal F, El-Serag HB, et al. Insurance status and treatment candidacy of hepatitis $C$ patients: analysis of population-based data from the United States. Hepatology. 2011;53:737-745.

33. Khallafi H, George N, Qureshi K. The prescribers' dilemma: treatment of hepatitis $\mathrm{c}$ infection for Medicaid insured patients in United States. Live Res Open J. 2015;1:26-31.

34. Bankhead C. Payers' perspectives: health economics outcomes in managed care. Am Health Drug Benefits. 2015;8:144-147.

35. Neuman T, Hoadley J, Cubanski J. The cost of a cure: Medicare's role in treating hepatitis C. 2014. Health Affairs Blog. Available at http:// healthaffairs.org/blog/2014/06/05/the-cost-of-a-cure-medicares-role-intreating-hepatitis-c/ Accessed May 15, 2016.

36. Canary LA, Klevens RM, Holmberg SD. Limited access to new hepatitis $C$ virus treatment under state Medicaid programs. Ann Intern Med. 2015; 163:226-228.

37. Mantravadi S. Hepatitis $C$ direct acting antivirals and disruptive innovation. Presented at Southwest Academy of Management Annual Meeting: Disruptive Innovation, Little Rock, AR, 2017. Available at www.swamfbd org/uploads/SWAM_Proceedings_2017.pdf Accessed April 3, 2017.

38. Center for Health Law and Policy Innovation of Harvard Law School. Examining hepatitis $C$ virus treatment access: a review of select state Medicaid fee-for-service and managed care programs. 2013. Available at www.chlpi.org/wp-content/uploads/2013/12/Examining_HCV_ Treatment_Access_Report.pdf Accessed March 20, 2015.

39. Healthy People 2020. Access to Health Services. 2017. Available at www.healthypeople.gov/2020/topics-objectives/topic/Access-to-HealthServices Accessed April 20, 2017.

40. Gordon SC, Lamerato LE, Rupp LB, et al. Prevalence of cirrhosis in hepatitis $\mathrm{C}$ patients in the Chronic Hepatitis Cohort Study (CHeCS): a retrospective and prospective observational study. Am J Gastroenterol. 2015;110:1169-1177.

41. Medicaid NADAC -National Average Drug Acquisition Cost. Pharmacy drug pricing. Available at www.medicaid.gov/Medicaid-CHIP-ProgramInformation/By-Topics/Benefits/Prescription-Drugs/PharmacyPricing.html Accessed January 18, 2017.

42. American Association for the Study of Liver Diseases and the Infectious Diseases Society of America. AASLD-IDSA. HCV Guidance: recommendations for testing, managing, and treating hepatitis C. 2016. Available at www.hcvguidelines.org/full-report-view Accessed July 28, 2016.

43. Chhatwal J, Kanwal F, Roberts MS, et al. Cost-effectiveness and budget impact of hepatitis $C$ virus treatment with sofosbuvir and ledipasvir in the United States. Ann Intern Med. 2015;162:397-406.

44. Gray AM, Clarke PM, Wolstenholme JL, et al. Applied Methods of Costeffectiveness Analysis in Health Care. Oxford, United Kingdom: Oxford University Press, 2011.

45. Mantravadi $S$. The oncogenic hepatitis $C$ virus and direct acting antivirals: economic implications for hepatocellular carcinoma in Medicaid beneficiaries with cirrhosis. Am J Manag Care. 2017;23:SP180-SP1844.

46. Clements KM, Clark RE, Lavitas $P$, et al. Access to new medications for hepatitis $C$ for Medicaid members: a retrospective cohort study. J Manag Care Spec Pharm. 2016;22:714-722b.
47. Center for Medicare \& Medicaid Services. Assuring Medicaid beneficiaries access to hepatitis C (HCV) drugs. 2015. Available at www.medicaid.gov/ Medicaid-CHIP-Program-Information/By-Topics/Benefits/PrescriptionDrugs/Downloads/Rx-Releases/State-Releases/state-rel-172.pdf Accessed June 12, 2016.

48. Bourgi K, Brar I, Baker-Genaw K. Health disparities in hepatitis C screening and linkage to care at an integrated health system in southeast Michigan. PLoS One. 2016;11:e0161241.

49. Lo Re V. Nearly half of hepatitis C patients on Medicaid denied coverage for life-saving drugs. Penn Researchers Rep. 2015. Available at www.pennmedicine.org/news/news-releases/2015/november/nearlyhalf-of-hepatitis-c-pat Accessed April 5, 2017.

50. Roy V, Choskhi D, Kissler S, et al. Making hepatitis $C$ a rare disease in the United States. 2016. Available at http://healthaffairs.org/blog/2016/06/15/makinghepatitis-c-a-rare-disease-in-the-united-states/ Accessed July 1, 2017.

51. Do A, Mittal Y, Liapakis A, et al. Drug authorization for sofosbuvir/ledipasvir (harvoni) for chronic HCV infection in a real-world cohort: a new barrier in the HCV care cascade. PLoS One. 2015;10:e0135645.

52. Graham J. Medicaid, private insurers begin to lift curbs on pricey hepatitis $V$ drugs. 2016. Available at http://khn.org/news/medicaid-private-insurersbegin-to-lift-curbs-on-pricey-hepatitis-c-drugs/ Accessed January 8, 2017.

53. Azar MM, Springer SA, Meyer JP, et al. A systematic review of the impact of alcohol use disorders on HIV treatment outcomes, adherence to antiretroviral therapy and health care utilization. Drug Alcohol Depend. 2010;112:178-193.

54. Malta M, Strathdee SA, Magnanini MM, et al. Adherence to antiretroviral therapy for human immunodeficiency virus/acquired immune deficiency syndrome among drug users: a systematic review. Addiction. 2008;1; 103:1242-1257.

55. Aspinall EJ, Corson S, Doyle JS, et al. Treatment of hepatitis C virus infection among people who are actively injecting drugs: a systematic review and meta-analysis. Clin Infect Dis. 2013;57(suppl_2): S80-S89.

56. Higgs P, Sacks-Davis R, Gold J, Hellard M. Barriers to receiving hepatitis C treatment for people who inject drugs: myths and evidence. Hepat Mon. 2011;11:513-518.

57. Data.Gov. Hepatitis C-Advanced Liver Disease Disparities Dashboard. 2017. Available at https://catalog.data.gov/dataset/hepatitis-c-advancedliver-disease-disparities-dashboard Accessed July 2, 2017.

58. Núñez A, Schilling JL. A space to promote intentional thoughtful action. Health Equity 2017;1:1-1.

Cite this article as: Mantravadi S (2017) Patterns in liver-related health outcomes with hepatitis $C$ virus treatments and health equity implications for decision makers: a cohort analysis of Medicaid patients, Health Equity 1:1, 156-164, DOI: 10.1089/heq.2017.0018.
Abbreviations Used
$\mathrm{DAA}=$ direct acting antiviral
$\mathrm{HCV}=$ hepatitis $\mathrm{C}$ virus

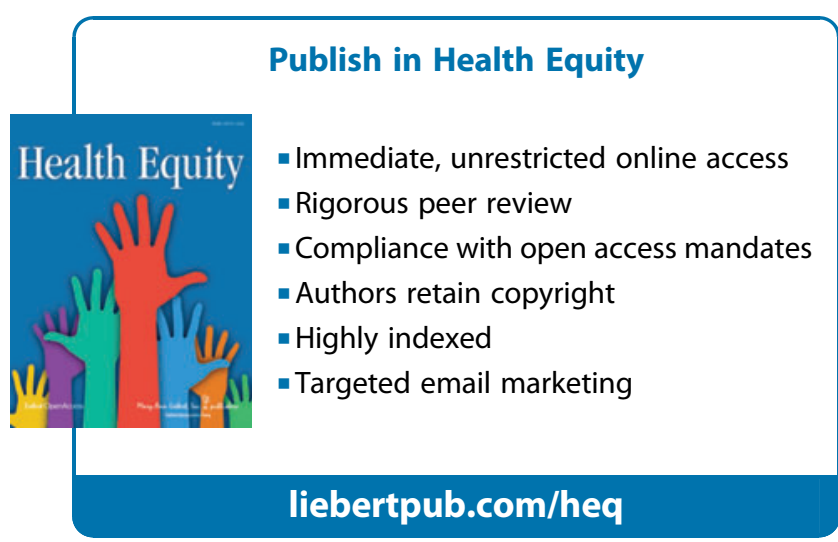

